\title{
DAYA TARIK WISATA PANTAI WEDIOMBO SEBAGAI ALTERNATIF WISATA BAHARI DI DAERAH ISTIMEWA YOGYAKARTA
}

\author{
Achmad Andi Rif'an \\ Program Studi S1 Hospitality/Ilmu Kepariwisataan \\ Sekolah Tinggi Pariwisata Ambarrukmo (STIPRAM) Yogyakarta \\ Jl. Ahmad Yani 52 Ringroad Timur, Yogyakarta 55281 Indonesia \\ Telp (+62 274) 485650, +62 85100487497, Fax. +62 274485214 \\ E-mail: andirifan@stipram.ac.id
}

\begin{abstract}
Abstrak
Daerah Istimewa Yogyakarta mempunyai begitu banyak wisata pantai yang bagus dan sangat menarik untuk dikunjungi. Salah satunya adalah Pantai Wediombo. Pantai ini belum begitu dikenal luas oleh wisatawan, dan masih kalah tenar dibandingkan pantaipantai lain di DIY. Penelitian ini bermaksud untuk memperkenalkan Pantai Wediombo sebagai alternatif wisata bahari di wilayah pesisir selatan DIY. Adapun tujuan dari penelitian ini adalah: mengetahui gambaran umum mengenai Pantai Wediombo; mengetahui atraksi wisata yang ditawarkan Pantai Wediombo; mengetahui aksesibilitas menuju lokasi Pantai Wediombo; dan mengetahui karakteristik wisatawan yang berkunjung ke Pantai Wediombo. Metode penelitian yang digunakan dalam studi ini adalah pendekatan kualitatif dengan menggunakan metode analisis deskriptif dengan menggunakan data primer yang didapat dari survey lapangan, dokumentasi, dan wawancara mendalam dengan pelaku usaha serta wisatawan. Pantai Wediombo memiliki berbagai atraksi atau daya tarik yang dapat menarik wisatawan untuk berkunjung, yang dapat diklasifikasikan menjadi something to see, something to do, dan something to buy. Aksesibilitas menuju Pantai Wediombo cukup mudah yang dapat ditempuh menggunakan kendaraan umum maupun kendaraan pribadi. Wisatawan yang berkunjung ke Pantai Wediombo memiliki karakteristik yang berbeda-beda yang dapat dilihat dari usia, jenis kelamin, pekerjaan, penghasilan, asal wisatawan, dan motivasi wisatanya.
\end{abstract}

Kata Kunci: Wisata Bahari, Daya Tarik, Aksesibilitas, Karakteristik Wisatawan

\begin{abstract}
DIY (Daerah Istimewa Yogyakarta/Special Region of Yogyakarta) coastal area has so many nice beaches that is very interesting to visit. One of them is Wediombo Beach. Wediombo Beach is not so well known by tourists yet, and still less famous than other beaches in DIY. This study intends to introduce Wediombo Beach as an alternative maritime tourism in the coastal area of DIY. The purpose of this research are: to identify the general profile of Wediombo Beach; to identify the tourist attractions offered Wediombo Beach; to identify the accessibility to the location of Wediombo Beach; and identify the characteristics of tourists visiting the Wediombo Beach. The method used in this study is a qualitative approach by using descriptive analysis using primary data obtained from the field survey, documentation, and in-depth interviews with official and the visitors/tourists. Wediombo Beach has many attractions that can attract tourists to visit, which can be classified as something to see, something to do, and something to buy. Accessibility to the beach Wediombo quite easily accessed which can be reached using public transport or private vehicles. Tourists visiting the beach Wediombo have different characteristics that can be seen from the age, gender, occupation, income, origin of tourists, and tourist motivation.
\end{abstract}

Keywords: Coastal Tourism, Attraction, Accessibility, Tourists Characteristic 


\section{PENDAHULUAN}

Indonesia mempunyai wilayah pesisir yang sangat luas yang membentang sepanjang Sabang hingga Merauke. Wilayah pesisir tersebut mempunyai banyak potensi yang bisa dimanfaatkan seperti potensi perikanan, kelautan, pertanian, energi dan juga pariwisata. Potensi pariwisata yang ada di wilayah pesisir dapat mendatangkan keuntungan baik bagi pemerintah maupun bagi masyarakat lokal yang tinggal di sekitar wilayah pesisir jika bisa dikelola dengan baik.

Wisata Bahari merupakan jenis pariwisata minat khusus dengan memanfaatkan potensi bentang alam laut dan wilayah kepesisiran baik yang dilakukan secara langsung seperti berperahu, berenang, snorkeling, diving, dan pancing maupun secara tidak langsung seperti olahraga pantai, piknik menikmati atmosfer laut (Nurisyah, 1998). Di satu sisi, jenis wisata ini memberikan dampak ekonomi peningkatan taraf hidup bagi masyarakat yang tinggal disekitarnya. Di sisi lain, secara ekologis wilayah pesisir yang dijadikan lokasi wisata bahari menjadi rentan terhadap bencana alam kepesisiran seperti banjir rob, erosi pantai, angin topan dan gelombang tsunami maupun dampak dari perubahan iklim (Rif'an, 2014; Kusmawan, 2013).

Potensi wilayah pesisir yang besar juga didukung oleh keindahan pemandangan pantai dan ekosistem khas yang ada disekitarnya. Penyiapan sarana dan prasarana yang optimal diperlukan guna mendukung pengembangan wisata bahari bagi pengunjung yang membutuhkan (Hidayat, 2011).

Propinsi Daerah Istimewa

Yogyakarta (DIY) memiliki potensi pariwisata bahari yang cukup besar. Wilayah pesisir tersebut mempunyai banyak pantai yang indah ditambah dengan keunikan ekosistemnya. Deretan pantai selatan wilayah DIY dari barat ke timur memang mempunyai daya tarik tersendiri bagi para wisatawan.

Salah satu pantai yang memiliki daya tarik yang indah adalah Pantai Wediombo yang terletak di wilayah pesisir Kabupaten Gunung Kidul. Pantai Wediombo memang belum begitu dikenal luas oleh wisatawan, baik yang berasal dari luar DIY maupun bagi wisatawan dan masyarakat DIY sendiri. Nama Pantai Wediombo masih kalah tenar dibandingkan pantai-pantai lain di DIY seperti Pantai Parangtritis, Pantai Depok, Pantai Glagah maupun Pantai Baron. Meskipun demikian Pantai Wediombo memiliki beberapa atraksi dan daya tarik yang tidak kalah jika dibandingkan dengan pantai-pantai lain di pesisir DIY. Pantai ini memiliki potensi wisata yang masih bisa dikembangkan lebih baik lagi.

Berdasarkan latar belakang yang telah disebutkan, maka penelitian ini bertujuan untuk: mengetahui gambaran umum mengenai Pantai Wediombo; mengetahui atraksi wisata yang ditawarkan Pantai Wediombo; mengetahui aksesibilitas menuju lokasi Pantai Wediombo; mengetahui karakteristik wisatawan yang berkunjung ke Pantai Wediombo.

\section{METODE PENELITIAN}

Wilayah penelitian adalah di Pantai Wediombo yang terletak di Desa Jepitu, Kecamatan Girisubo, Kabupaten Gunung Kidul, Propinsi Daerah Istimewa Yogyakarta (DIY). Metode penelitian yang digunakan dalam studi ini adalah pendekatan kualitatif dengan menggunakan metode analisis deskriptif dengan menggunakan data primer yang didapat dari survey lapangan. Karakteristik penelitian kualitatif akan lebih banyak mementingkan segi proses dibanding hasil penelitian. Penelitian kualitatif menggunakan data yang bersifat kualitatif, dan tahapan pelaksanaannya bisa berbeda antara satu sama lainnnya (Wardiyanta, 2006). 


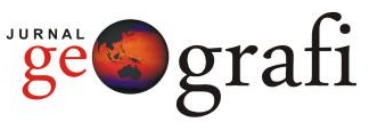

Pada penelitian ini penulis mencoba menggali informasi dan data sebanyak mungkin dari lapangan. Teknik pengumpulan data adalah dengan melakukan observasi lapangan, dokumentasi gambar dengan kamera, dan wawancara mendalam dengan pelaku usaha serta pengunjung/wisatawan yang berkunjung di Pantai Wediombo dengan cara membagikan kuesioner. Analisis data dilakukan dari data sekunder yang diperoleh serta dari data survei lapangan. Analisis dilakukan secara deskriptif kualitatif untuk menjawab tujuan penelitian. Penelitian ini selain bertujuan membuat deskripsi atas suatu fenomena sosial dan alam secara sistematis, faktual dan akurat, juga melakukan eksplorasi terhadap kondisi empirik yang didasari dengan sumber kebenaran umum yang bersifat kualitatif.

\section{HASIL DAN PEMBAHASAN Gambaran Umum Kabupaten Gunung Kidul}

Kabupaten Gunungkidul terletak di bagian tenggara Propinsi Daerah Istimewa Yogyakarta dan berbatasan langsung dengan Samudera Hindia. Kabupaten ini merupakan salah satu dari lima kabupaten/kota yang berada di propinsi DIY selain Kota Yogyakarta,
Kabupaten Sleman, Kabupaten Bantul, dan Kabupaten Kulonprogo. Sebagian besar wilayah kabupaten ini berupa perbukitan dan pegunungan kapur atau karst, yakni bagian dari Pegunungan Sewu.

Kabupaten Gunungkidul berbatasan dengan Kabupaten Klaten dan Kabupaten Sukoharjo di sebelah utara, Samudera Hindia di sebelah selatan, Kabupaten Sleman dan Kabupaten Bantul di sebelah barat, serta Kabupaten Wonogiri di sebelah timur.

Ibukota atau pusat kabupaten berada di Kecamatan Wonosari yang letaknya tepat di tengah-tengah kabupaten. Kabupaten Gunungkidul terdiri dari 18 kecamatan yaitu Kecamatan Tanjungsari, Kecamatan Semanu, Kecamatan Ngawen, Kecamatan Gedang Sari, Kecamatan Patuk, Kecamatan Girisubo, Kecamatan Semin, Kecamatan Paliyan, Kecamatan Playen, Kecamatan Wonosari, Kecamatan Karangmojo, Kecamatan Ngelipar, Kecamatan Ponjong, Kecamatan Rongkop, Kecamatan Sapto Sari, Kecamatan Ponggong, Kecamatan Tepus, dan Kecamatan Purwosari. Untuk lebih jelasnya mengenai wilayah Kabupaten Gunungkidul, dapat dilihat pada Gambar 1 di bawah ini.

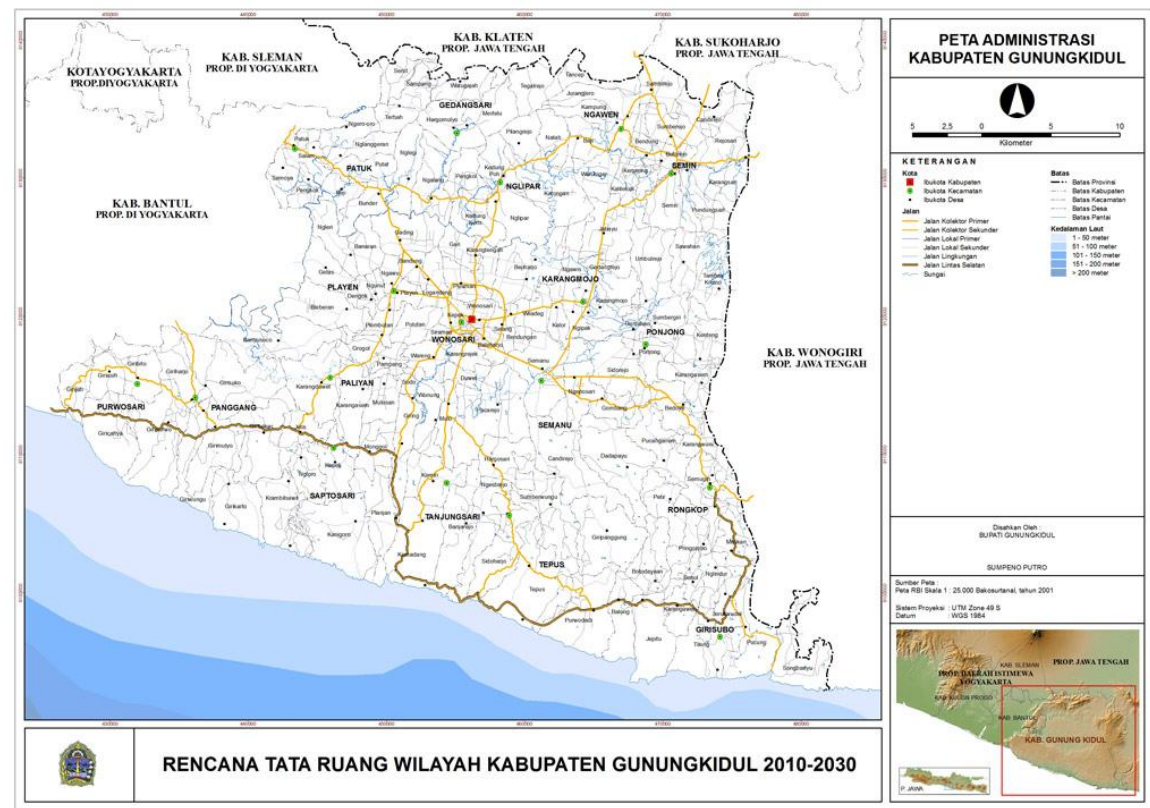

Gambar 1. Peta Administrasi Kabupaten Gunungkidul (Sumber: RTRW Kabupaten Gunungkidul Tahun 2010-2030) 


\section{Gambaran Umum Pantai Wediombo}

Pantai Wediombo terletak di Desa Jepitu kecamatan Girisubo, Kabupaten Gunungkidul, Daerah Istimewa Yogyakarta, sekitar $30 \mathrm{~km}$ arah tenggara kota Wonosari. Pantai yang masih alami, berbentuk teluk dan landai dengan hamparan pasir putih. Pantai Wediombo berada pada kawasan karst yang menjadi obyek wisata. Pantai ini menjadi salah satu situs dari Kawasan Geopark Gunung Sewu yang sejak September 2015 ditetapkan sebagai Geopark atau taman bumi warisan dunia yang diakui UNESCO atau dikenal dengan nama UNESCO Global Geopark.

Nama Wediombo yang dalam Bahasa Jawa berarti pasir/hamparan pasir yang luas sebenarnya tidak sesuai dengan keadaan pantai yang sesungguhnya, karena hamparan pasir yang ada disana tidak begitu luas dan dibatasi 2 bukit karang. Pantai ini terletak di sebuah teluk atau lautan yang menjorok ke daratan dan lebih pantas bila dinamakan Teluk Ombo atau teluk yang luas.

Ketika kita sampai di area parkir Pantai Wediombo, kita tidak bisa langsung sampai pada pantainya. Kita harus melewati beberapa anak tangga dan turun ke bawah sebelum sampai ke lokasi. Sambil jalan menuruni anak tangga kita bisa melihat pemandangan desa di sekitar pantai, rumah penduduk, hutan mangrove, dan ladang tempat penduduk bercocok tanam. Gambar 2 memperlihatkan denah Pantai Wediombo.

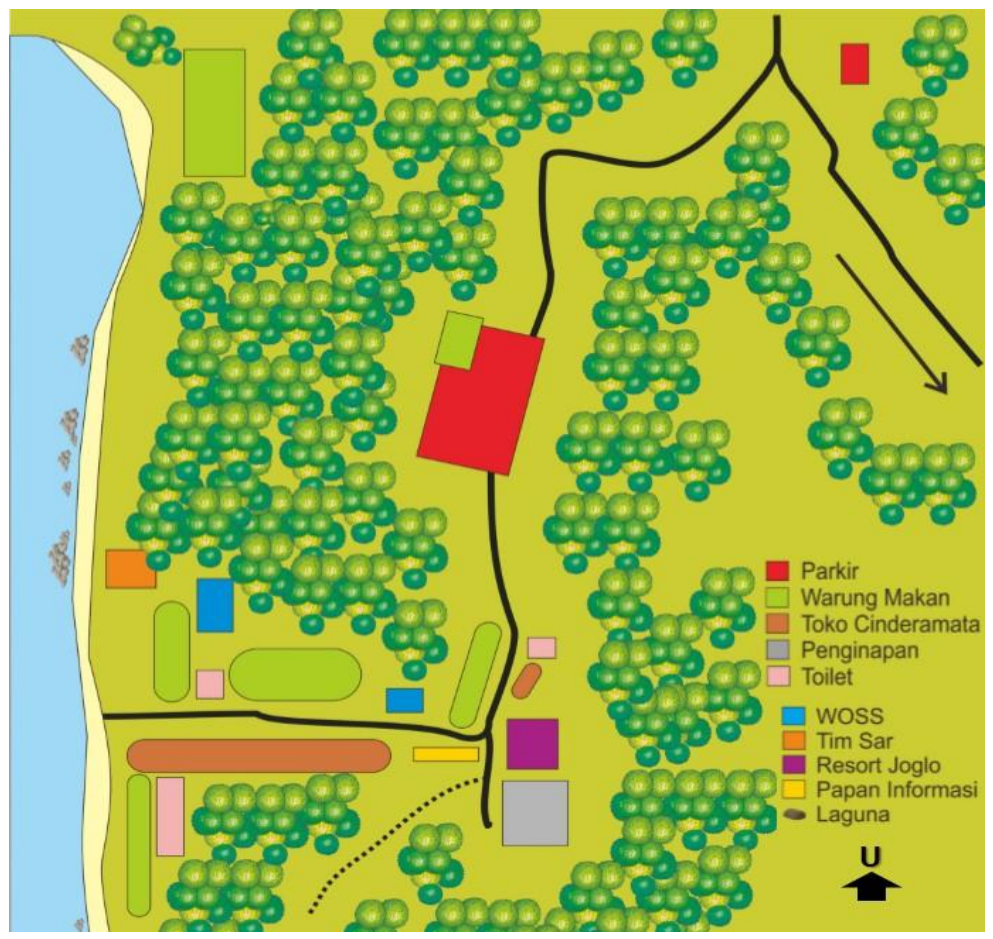

Gambar 2. Denah Kawasan Pantai Wediombo

\section{Atraksi Pantai Wediombo}

Atraksi atau daya tarik wisata merupakan sesuatu yang dapat menarik seseorang menuju ke suatu destinasi dan merupakan alasan utama bagi seseorang yang melakukan kegiatan pariwisata. Ada tiga syarat yang harus dipenuhi agar suatu tempat bisa menjadi daya tarik wisata, yaitu ada sesuatu yang bisa dilihat, sesuatu yang bisa dikerjakan, dan sesuatu yang bisa dibeli (Soekadijo, 2000; Karyono, 1997; Rif'an, 2016). Pantai Wediombo merupakan salah satu daya tarik wisata alam yang cukup terkenal di Kabupaten Gunungkidul dan termasuk dalam pantai baru yang dikelola oleh 


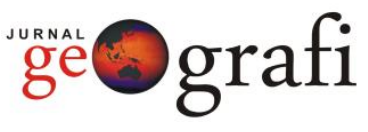

pemerintah. Keberadaannya didukung pula oleh obyek wisata alam lainnya yang juga menjadi situs Geopark Gunung Sewu seperti Gunungapi Purba Nglanggeran, Goa Pindul, Kali Suci, dansitus wisata lain.

Pantai Wediombo menawarkan beberapa atraksi yang bisa dinikmati oleh wisatawan. Atraksi-atraksi tersebut dapat dikelompokkan menjadi 3: something to see, something to do, dan something to buy.

\section{Something To See}

- Pemandangan Pantai dan Hamparan Pasir Putih

Pantai Wediombo termasuk pantai yang bersih dan kualitas airnya jernih. Ditambah dengan pemandangan terumbu karang yang cantik, batu karang yang besar biota laut yang beragam, menjadi daya tarik bagi wisatawan. Pantai ini menyuguhkan pemandangan pantai cantik yang luar biasa dan pada siang hari yang cerah air lautnya terlihat berwarna kebiruan cerah. Pasir putihya yang cerah masih sangat terjaga, dihiasi serpihan cangkang yang telah ditinggalkan kerangnya.

\section{- Melihat Sunset}

Pantai wediombo menghadap kebarat sehingga menjadi tempat strategis untuk menyaksikan matahari tenggelam atau sunset pada sore hari yang terlihat indah.

- Melihat Upacara Ngalalangi

Pantai Wediombo berbatasan langsung dengan desa pesisir. Di desa tersebut pada Bulan April dilakukan upacara adat guna memohon keselamatan maupun berkat yang melimpah. Upacara adat tersebut dinamakan Upacara Ngalalangi, yaitu upacara penangkapan ikan dengan menggunakan alat penangkap tradisional yang terbuat dari akar pohon wawar. Pada upacara adat ini banyak masyarakat desa yang mengikuti dan menjadi tontonan menarik bagi wisatawan. Gambar 3 menunjukkan something to see yang ada di Pantai Wediombo.
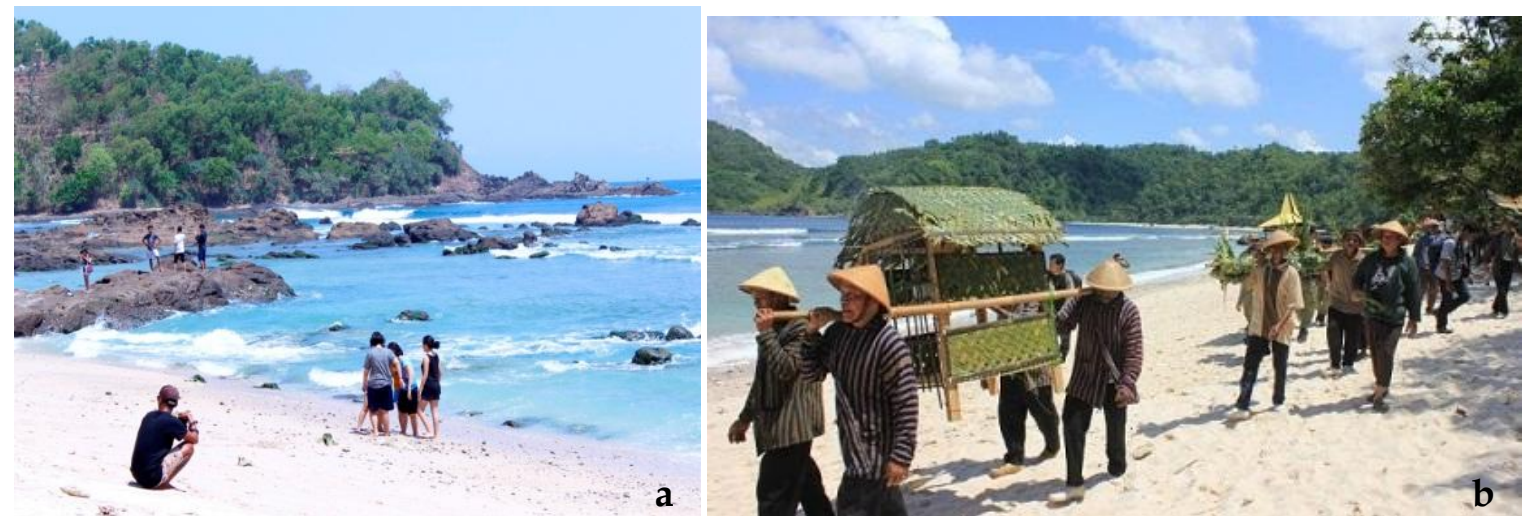

Gambar 3. Something to See di Pantai Wediombo berupa Pemandangan Pantai (a) dan Upacara Ngalalagi (b)

\section{Something to Do}

- Memancing Ikan

Pengunjung Wediombo, selain menikmati pemandangan pantai, juga bisa melakukan beberapa kegiatan di pantai ini, diantaranya adalah memancing ikan di ketinggian bukit karang. Bukit karang ini letaknya cukup jauh dari pantai dan bisa dijangkau setelah berjalan ke arah timur menyusuri bibir pantai, naik turun karang di tepian pantai yang cukup terjal.

\section{- Berenang, Surfing dan Snorkeling}

Kondisi ombaknya yang besar sangat cocok untuk aktivitas surfing. Selain itu, keindahan bawah laut juga menarik untuk melakukan snorkeling. Bagi yang tidak membawa peralatan surfing dan snorkeling, disana ada tempat 
persewaan. Seperti yang banyak dijumpai pada wisata pantai lain, pengunjung dapat melakukan juga aktivitas seperti berenang. Berenang di Wediombo agak berbeda karena seperti berenang di kolam

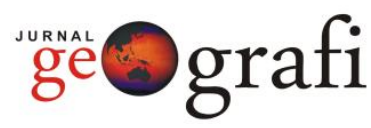

yang terbuat secara alami jika surut yaitu berupa teluk yang disekitarnya terdapat batu karang pemecah ombak. Gambar 4 menunjukkan aktivitas yang bisa dilakukan di Pantai Wediombo.
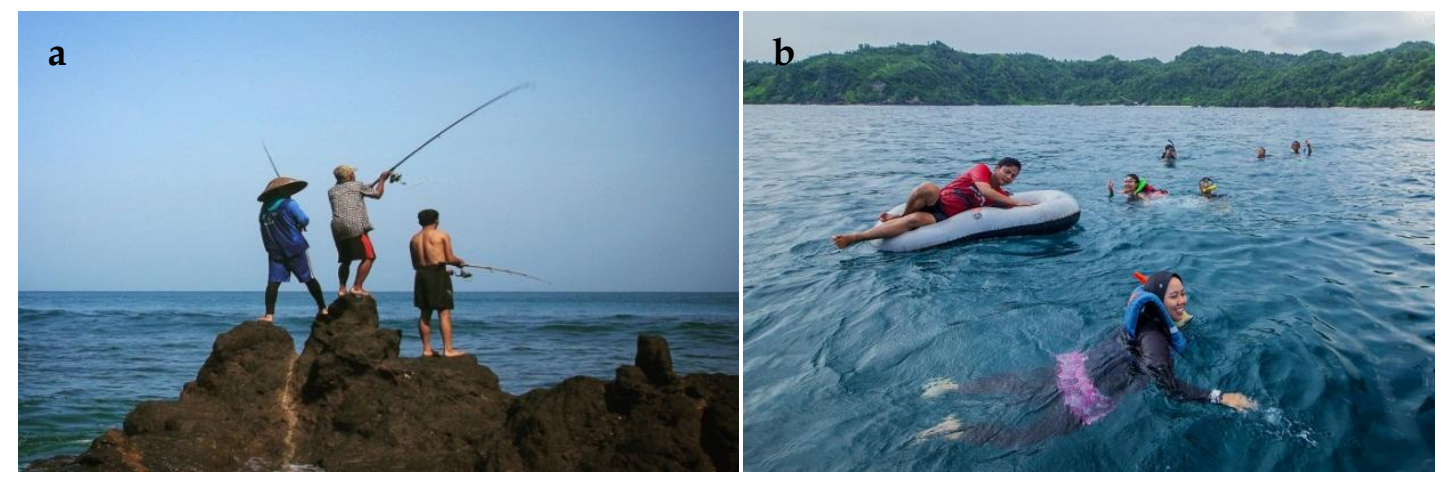

Gambar 4. Something to Do di Pantai Wediombo berupa kegiatan memancing (a) berenang dan snorkeling $(b)$

\section{Something to Buy}

Selain melihat panorama dan melakukan aktivitas di Pantai Wediombo, kurang lengkap rasanya bila tidak membeli sesuatu. Di Pantai Wediombo terdapat beberapa toko atau warung yang wisatawan bisa membeli disana. Salah satunya adalah warung makan, tempat wisatawan membeli makan dan minum bila tidak membawa bekal dari rumah.
Selain itu juga terdapat toko souvenir yang menjual aneka pernak-pernak dan cinderamata yang bisa dibawa pulang sebagai oleh-oleh untuk keluarga atau teman. Gambar 5 menunjukkan toko souvenir tempat wisatawan membeli oleh-oleh di Pantai Wediombo.

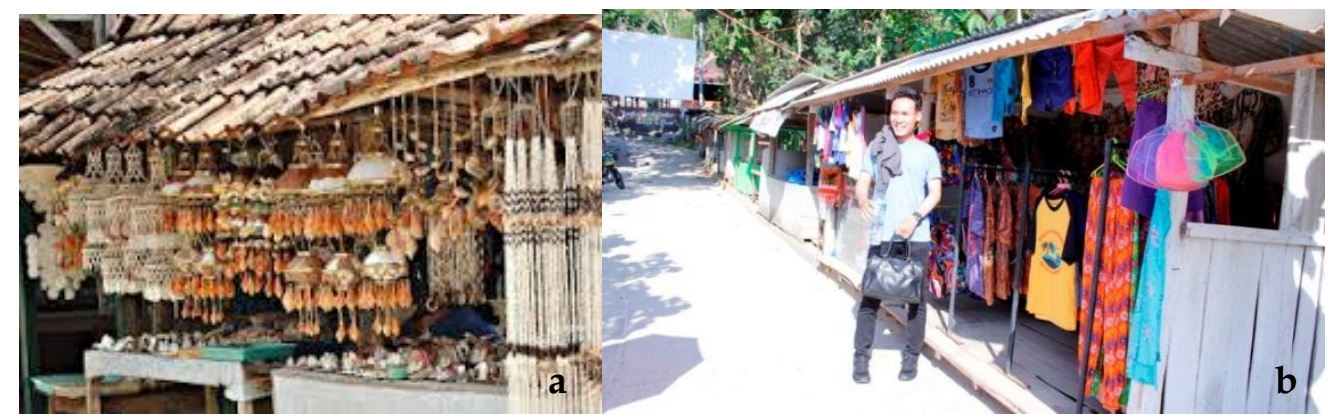

Gambar 5. Something to Buy di Pantai Wediombo (a dan b)

\section{Aksesibilitas Menuju Pantai Wediombo}

Pantai Wediombo berjarak kurang lebih 30 kilometer dengan ibukota Kabupaten Gunungkidul, yaitu Wonosari dan 60 kilometer dengan ibukota Propinsi DIY. Aksesibilitas jalan dari Kota Yogyakarta ke Gunungkidul cenderung sudah baik untuk dilewati kendaraan kecil maupun besar. Jalan-jalan besar sudah mulai diperbaiki. Akan tetapi jalanjalan kecil menuju pantai belum bisa dilalui bus-bus besar terutama bus umum dikarenakan ke depannya pengembangan pantai-pantai di Gunungkidul cenderung untuk konservasi.

Pantai Wediombo ini bisa dijangkau dengan kendaraan pribadi atau kendaraan umum. Kendaraan umum yang ada biasanya berupa mini bus dengan rute Yogyakarta - Wonosari. Jika naik transportasi umum, dari kota Wonosari, bisa melanjutkan perjalanan dengan mini bus ke Pantai Baron baru kemudian ke Pantai Wediombo. Namun 


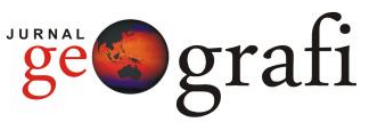

mini bus umum hanya beroperasi pada hari libur saja (forum.detik.com).

Bagi wisatawan yang menggunakan kendaraan pribadi bisa menempuh dari jalur Wonosari- Semanu - Jepitu Wediombo. Selain itu bisa juga dengan cara menyusuri pantai-pantai di Gunungkidul, yaitu Pantai Tepus, Pantai Girisubo hingga sampai di Pantai Wediombo.

\section{Karakteristik Wisatawan Pantai Wediombo}

Wisatawan merupakan komponen dalam pariwisata yang mempunyai peran yang penting. Mengetahui karakteristik wisatawan merupakan langkah dalam pengembangan pariwisata berdasarkan persepsi wisatawan. Karakteristik wisatawan dapat menunjukkan bagaimana perilaku wisatawan sebagai konsumen pariwisata. Perilaku serta motivasi wisatawan ini dapat dijadikan acuan untuk para pelaku pariwisata dari mulai pemerintah, penyedia jasa wisata, pengelola tempat wisata dalam menentukan kebijakan-kebijakan maupun keputusan yang sesuai dengan keinginan dan kebutuhan dari wisatawan itu sendiri. Hal ini juga menjadi salah satu kunci untuk menjamin perkembangan suatu destinasi wisata. Untuk menciptakan persepsi yang positif, maka suatu daya tarik wisata dituntut untuk memenuhi keinginan wisatawan (Nieamah, 2014; Sayangbatti dan Baiquni, 2013).

Karakteristik wisatawan yang berkunjung ke Pantai Wediombo dapat diketahui dari wawancara dan kuesioner yang disebarkan kepada wisatawan. Terdapat beberapa parameter yang dapat mewakili karakteristik wisatawan yang berkunjung ke Pantai Wediombo. Parameter itu adalah usia, jenis kelamin, pekerjaan, penghasilan, asal wisatawan, dan motivasi wisatawan. Berikut karakteristik wisatawan berdasarkan parameter-parameter tersebut.

- Usia

Berdasarakan wawancara terhadap wisatawan, didapatkan data bahwa mayoritas wisatawan yang berkunjung ke Pantai Wediombo berusia di atas 20 tahun yaitu sekitar $80 \%$, sedangkan sisanya sebesar $20 \%$ berusia dibawah 20 tahun. Gambar 6 menunjukkan diagram wisatawan berdasarkan usia.

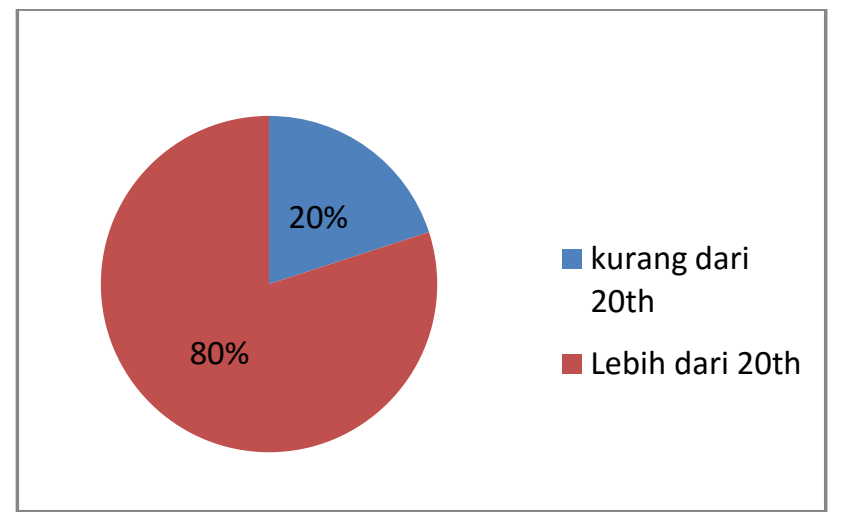

Gambar 6. Karakteristik Wisatawan Berdasarkan Usia

\section{- Jenis Kelamin}

Berdasarkan jenis kelamin, jumlah wisatawan yang berkunjung ke Pantai Wediombo sebanding antara laki-laki dan perempuan. Laki-laki sekitar 50\% dan perempuan juga 50\%. Gambar 7 menunjukkan diagram wisatawan berdasarkan jenis kelamin. 


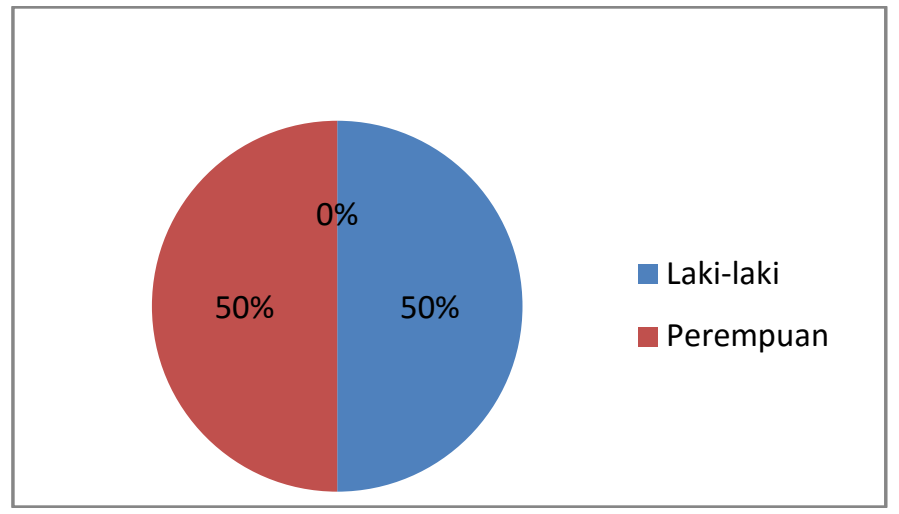

Gambar 7. Karakteristik Wisatawan Berdasarkan Jenis Kelamin

\section{- Pekerjaan}

Berdasarakan kuesioner, didapatkan data bahwa mayoritas wisatawan yang berkunjung ke Pantai Wediombo adalah pelajar/mahasiswa yakni sekitar $58 \%$.
Terbanyak kedua adalah sebagai pegawai swasta $23 \%$. Wiraswasta $10 \%$ dan sisanya sekitar $10 \%$ pekerjaan lainnya. Gambar 8 menunjukkan diagram wisatawan berdasarkan pekerjaan.

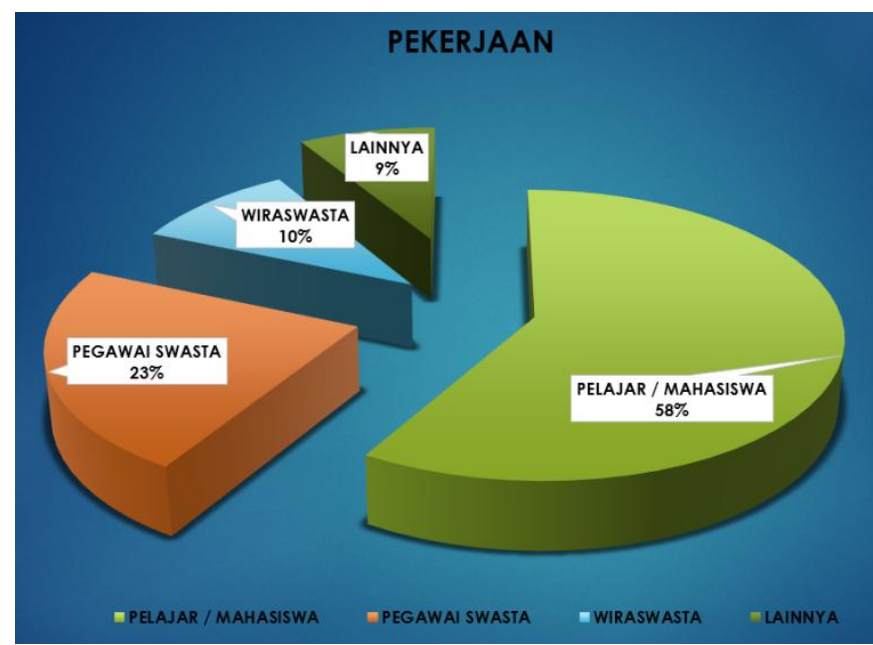

Gambar 8. Karakteristik Wisatawan Berdasarkan Pekerjaan

\section{- Penghasilan}

Wisatawan pada umumnya enggan memberitahukan berapa besar penghasilan mereka. Maka karakteristik wisatawan Pantai Wediombo berdasarkan penghasilan hanya dibedakan antara wisatawan yang sudah berpenghasilan dan wisatawan yang belum berpenghasilan. Sebanyak $70 \%$ wisatawan belum berpenghasilan, dan 30\% sudah memiliki penghasilan sendiri. Gambar 9 menunjukkan diagram wisatawan berdasarkan penghasilan.

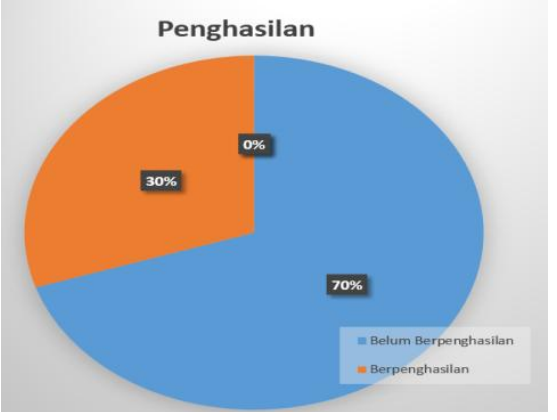

Gambar 9. Karakteristik Wisatawan Berdasarkan Penghasilan 


\section{- Asal Wisatawan}

Karakteristik Wisatawan berdasarkan asal daerah menunjukkan bahwa 70\% wisatawan berasal dari dalam DIY dan
30\% wisatawan dari luar DIY. Gambar 10 menunjukkan diagram wisatawan berdasarkan asal wisatawan.

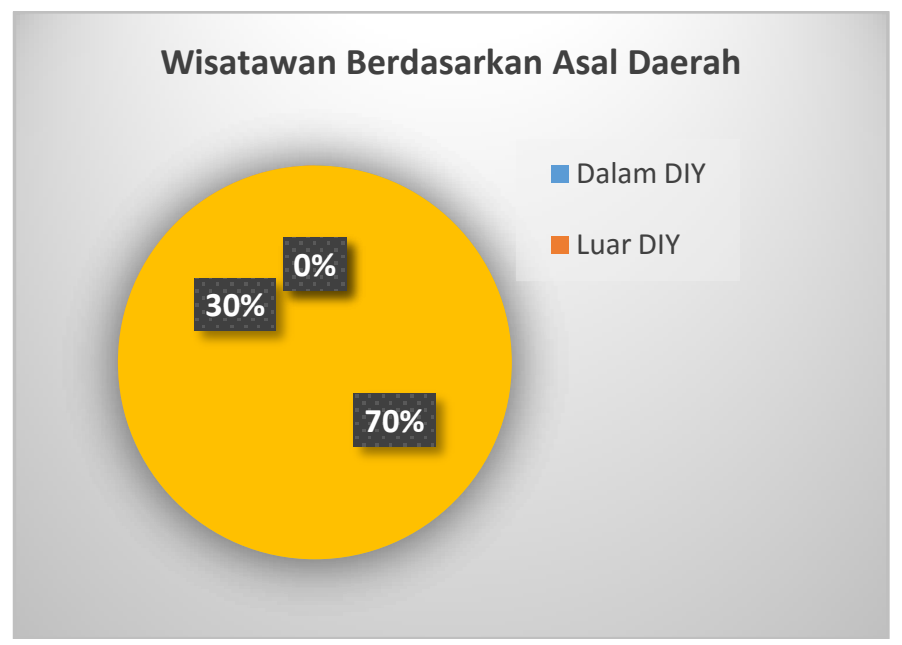

Gambar 10. Karakteristik Wisatawan Berdasarkan Asal Wisatawan

- Motivasi Wisatawan

Motivasi atau tujuan wisatawan dalam melakukan perjalanan wisata berbeda-beda antara satu sama lain. Berdasarkan kuesioner, mayoritas wisatawan yang berkunjung ke Pantai Wediombo memiliki motivasi untuk rekreasi yakni sebesar $67 \%$ dari total wisatawan. Motivasi terbanyak kedua adalah untuk melakukan refreshing sebanyak $17 \%$. Sedangkan motivasi yang lain adalah Sisanya sebanyak $8 \%$ untuk mencari pengalaman baru dan motivasi lain. Gambar 11 menunjukkan diagram wisatawan berdasarkan motivasi wisatawan.

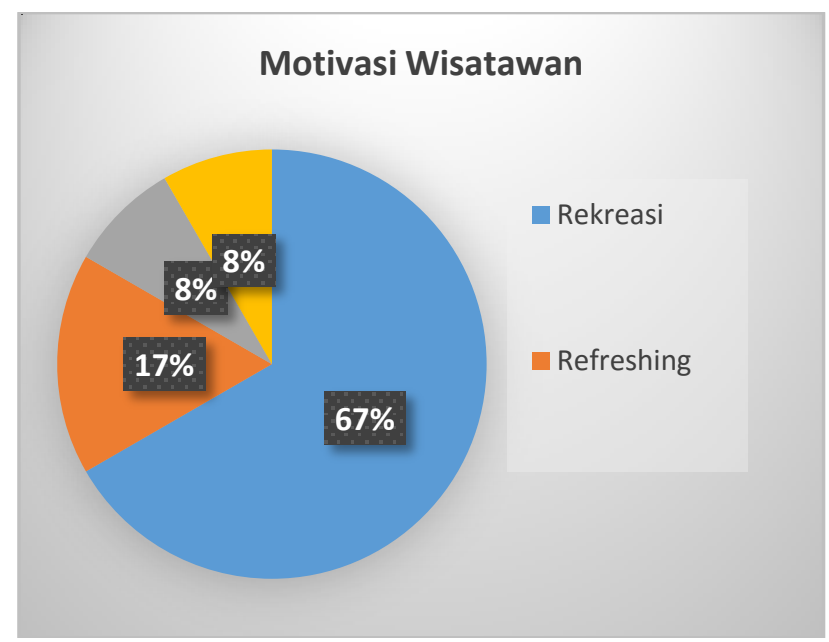

Gambar 11. Karakteristik Wisatawan Berdasarkan Motivasi Wisatawan

\section{KESIMPULAN DAN SARAN Kesimpulan}

Berdasarkan data yang didapat dari lapangan serta analisis yang telah dilakukan, maka dapat diambil beberapa kesimpulan sebagai berikut:

1. Pantai Wediombo merupakan salah satu DTW (daya tarik wisata) di Kabupaten Gunung Kidul, DIY yang 
merupakan jenis wisata bahari dan merupakan rangkaian dari wisatawisata pantai di wilayah pesisir DIY.

2. Pantai Wediombo memiliki berbagai atraksi atau daya tarik yang dapat menarik wisatawan untuk berkunjung, yang dapat diklasifikasikan menjadi something to see, something to do, dan something to buy, dimana atraksi-atraksi tersebut tidak kalah jika dibandingkan dengan wisata bahari lain. Dengan demikian pantai ini dapat menjadi alternatif wisata bahari di DIY.

3. Aksesibilitas menuju Pantai Wediombo cukup mudah yang dapat ditempuh dari Kota Yogyakarta maupun dari pusat Kota Wonosari. Wisatawan dapat menggunakan kendaraan umum maupun kendaraan pribadi.

4. Wisatawan yang berkunjung ke Pantai Wediombo memiliki karakteristik yang berbeda-beda yang dapat dilihat dari usia, jenis kelamin, pekerjaan, penghasilan, asal wisatawan, dan motivasi wisatawannya.

\section{Saran}

Beberapa saran yang diberikan kepada pengelola Pantai Wediombo dan Pemerintah Daerah adalah sebagai berikut::

1. Masih perlu diolahnya lahan dengan menambahkan sedikit atraksi buatan sehingga menambah daya tarik daripantai tersebut.

2. Fasilitas diharapkan dapat lebih memadai seperti toilet, resto, mini market, penginapan, dan lain -lain.

3. Disediakannya banyak tempat sampah yang memadai dan beberapa ajakan untuk menjaga kebersihan dan kelestarian pantai Wediombo.

\section{DAFTAR PUSTAKA}

Bappeda Kabupaten Gunungkidul. (2010). Rencana Tata Ruang Wilayah
Kabupaten Gunungkidul Tahun 20102030.

Hidayat, M. (2016). Strategi Perencanaan Dan Pengembangan Objek Wisata (Studi Kasus Pantai Pangandaran Kabupaten Ciamis Jawa Barat). Tourism \& Hospitality Essentials (THE) Journal, 1(1), 33-44.

Karyono, H. (1997). Kepariwisataan. Jakarta: PT. Gramedia Widiasarana Indonesia.

Nieamah, K. F. (2014). Persepsi Wisatawan Mancanegara Terhadap Fasilitas Dan Pelayaan Di Candi Prambanan. Jurnal Nasional Pariwisata, 6(1), 39-45.

Nurisyah, S. (2001). Rencana pengembangan fisik kawasan wisata bahari di wilayah pesisir Indonesia. Buletin Taman Dan Lanskap Indonesia. Perencanaan, Perancangan dan Pengelolaan, 3(2).

Rif'an, A. A. (2014). Pemilihan Lokasi Pengembangan Pemukiman sebagai Upaya Adaptasi terhadap Banjir Pasang dan Perubahan Garis Pantai. Tesis. Yogyakarta: Universitas Gadjah Mada.

Rif'an, A. A. (2016). Tourism Components and Tourists Characteristic of Prambanan Temple as The World Culture Heritage Site in Yogyakarta, Indonesia. International Journal of Tourism and Hospitality Study, 1(1).

Sayangbatti, D. P., \& Baiquni, M. (2012). Motivasi dan Persepsi Wisatawan Tentang Daya Tarik Destinasi Terhadap Minat Kunjungan Kembali di Kota Wisata Batu. Jurnal Nasional Pariwisata, 5(2), 126-136.

Soekadijo, R. G. (2000). Anatomi Pariwisata (Memahami Pariwisata sebagai Systemic Linkage). Jakarta : PT. Gramedia Pustaka Umum

Kusmawan, A. T. (2013). Pengaruh Perubahan Iklim terhadap Kagiatan Wisata Bahari di Gili Trawangan. Jurnal Nasional Pariwisata, 5(2), 137145.

Wardiyanta. (2006). Metode Penelitian Pariwisata. Yogyakarta: ANDI. 
ge Ografi

http://forum.detik.com/pantai-favoritpara-pemancing-di-yogyakarta-
Available at http://jurnal.unimed.ac.id/2012/index.php/geo e-ISSN: 2549-7057 | p-ISSN: 2085-8167

t1330332.html diakses tanggal 5 Agustus 2016 